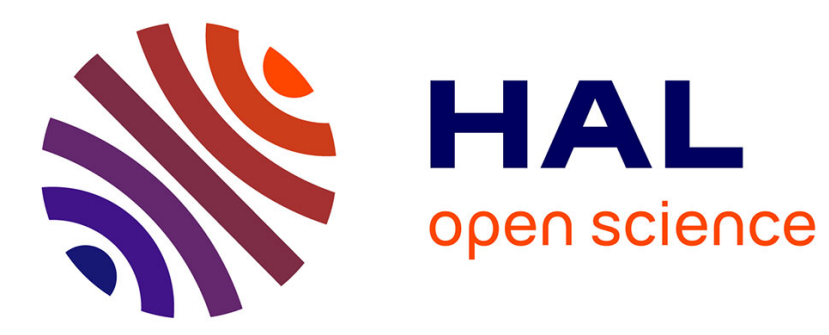

\title{
Seabird colonies as relevant sources of pollutants in Antarctic ecosystems: Part 2 - Persistent Organic Pollutants
}

C.V.Z. V Z Cipro, P. Bustamante, S. Taniguchi, J. Silva, M.V. V Petry, R.C. C Montone

\section{To cite this version:}

C.V.Z. V Z Cipro, P. Bustamante, S. Taniguchi, J. Silva, M.V. V Petry, et al.. Seabird colonies as relevant sources of pollutants in Antarctic ecosystems: Part 2 - Persistent Organic Pollutants. Chemosphere, 2019, 214, pp.866-876. 10.1016/j.chemosphere.2018.09.030 . hal-02338813

\section{HAL Id: hal-02338813 https://hal.science/hal-02338813}

Submitted on 30 Oct 2019

HAL is a multi-disciplinary open access archive for the deposit and dissemination of scientific research documents, whether they are published or not. The documents may come from teaching and research institutions in France or abroad, or from public or private research centers.
L'archive ouverte pluridisciplinaire HAL, est destinée au dépôt et à la diffusion de documents scientifiques de niveau recherche, publiés ou non, émanant des établissements d'enseignement et de recherche français ou étrangers, des laboratoires publics ou privés. 
Seabird colonies as relevant sources of pollutants in Antarctic ecosystems: Part 2 - Persistent Organic Pollutants

Cipro, C.V.Z. ${ }^{1,2^{*}}$, Bustamante, P. ${ }^{2}$, Taniguchi, S. ${ }^{1}$, Silva, J. ${ }^{1}$, Petry, M.V. ${ }^{3}$ and Montone, R.C. ${ }^{1}$

${ }^{1}$ Laboratório de Química Orgânica Marinha, Instituto Oceanográfico (LabQOM), Universidade de São Paulo, Praça do Oceanográfico n ${ }^{\circ}$ 191, 05508-120 São Paulo, SP, Brazil

${ }^{2}$ Littoral Environnement et Sociétés (LIENSs), UMR 7266, CNRS-Université de La Rochelle, 2 rue Olympe de Gouges 17042 La Rochelle Cedex 01, France

${ }^{3}$ Laboratório de Ornitologia e Animais Marinhos, Universidade do Vale do Rio dos Sinos, Av. Unisinos n ${ }^{\circ} 950$, Cristo Rei, São Leopoldo, Rio Grande do Sul, 93022-750, Brazil

* Corresponding author: caiovzc@usp.br 
Abstract: Despite typically not being taken into account (usually in favour of the "Global Distillation" process), the input of Persistent Organic Pollutants (POPs) via biological activity can be indeed relevant at the local scale in terrestrial Polar environments when seabird colonies are considered. The fact that seabirds bioaccumulate and biomagnify those POPs, gather in large numbers and excrete on land during their reproductive season can act locally as relevant secondary source of the same contaminants. The first part of this study indicated that these colonies act as so for several essential and non-essential trace elements and this second part tests the same hypothesis concerning POPs using the very same samples. Lichens $(n=55)$, mosses $(n=58)$ and soil $(n=37)$ were collected in 13 locations within the South Shetlands Archipelago during the austral summers of 2013-14 and 2014-15. They were divided in colony (within the colony itself for soil and bordering it for vegetation) and control (at least 150m away from any colony interference), analysed for POPs: organochlorine pesticides, polychlorinated byphenyls (PCBs) and polybrominated diphenyl ethers (PBDEs); and stable isotopes ( $\mathrm{C}$ and $\mathrm{N}$ ). Results showed that colonies act clearly as a secondary source for PCBs and likely for HCB. As in the first part, probable local sources other than the colonies themselves are hypothesised due to high concentrations found in control sites. Again, soil seemed the most adequate matrix for the intended purposes especially because of some particularities in the absorption of animal derived organic matter by vegetation, pointed out by stable isotope analyses.

Keywords: Antarctica, secondary sources, stable isotopes, POPs, PCBs, Organochlorine pesticides 


\section{1 - Introduction}

As presented in part 1 of our work (Cipro et al., 2018a), "global distillation", the mechanism by which contaminants volatilise in warmer locations with subsequent atmospheric long-range transport and condensation in colder regions is majorly held responsible as the main, or even the only pollutant input process in Polar environments, whilst the biologically mediated transport is frequently not taken into account (Blais et al., 2005; Blais et al., 2007). However, literature presents evidences suggesting the role of seabird colonies as relevant secondary sources at the local or regional level for both organic and inorganic contaminants (Cipro et al., 2018a, 2011; Roosens et al., 2007). The particular fact that several species of seabirds assemble in colonies containing a large number of individuals (penguins, for instance, may form colonies of hundreds of thousands of individuals, e.g., Ballance et al., 2009) excreting on land, notably during the reproductive season, results in a substantial input regarding the terrestrial ecosystems in and around such colonies.

This input from seabird colonies added to the organic matter deriving from eggs (Brasso et al., 2012), bird tissues and prey present in these structures (Emslie et al., 2014) represent the major source of nutrients for Antarctic terrestrial ecosystems (Smykla et al., 2007). This is verified for both extant and abandoned colonies (Liu et al., 2006; Outridge et al., 2016; Tatur et al., 1997). The availability of the nutrients resulting from this input induces a pattern of green algae/cyanobacteria, Antarctic hair-grass, mosses and lichens, in this order, as the distance to the colony increases (Smykla et al., 2007). In this regard, water availability also plays an important role considering the differences in water dependency from these organisms but also seasonal melting and runoff water are known to have a key influence in marine primary production (Anderson and Polis, 1999) and in carrying organic contaminants (Cipro et al., 2017b) to be absorbed by marine life (Cipro et al., 2018b). This introduction of nutrients brings contaminants along, not only by a direct influence of the excretion (Rudolph et al., 2016), but also through cycles of resuspension and redeposition, for instance.

The suitability of the matrixes for this objective (the assessment of seabird colonies as secondary contaminants sources) is largely confirmed by literature (e.g. Borghini et al., 2005; Cocks et al., 1998; Negoita et al., 2003; Tarcau et al., 2013). However, differently from the trace elements presented in the first part of the present study (Cipro et al. 2018a), the Persistent Organic Pollutants (POPs) analysed in this second part do not present natural environmental sources, but only anthropic ones. Due to their physico-chemical properties (mainly stability, lipophilicity and vapour pressure), POPs 1) are transported through long distances through the 
atmospheric pathway; 2) undergo an increase of their concentrations during the lives of the organisms (i.e. bioaccumulation process) and also according to their trophic position (i.e. biomagnification process). The cold conditions of Antarctic environments favour the persistency of these compounds with respect to temperate and tropic environments, particularly because of the seasonal storage and consumption of lipids in these environments (Cipro et al., 2013; Loganathan and Kannan, 1991).

Taking all the previous considerations into account, in an analogous manner to the first part of the study, the work had as an aim, to assess seabird colonies as secondary sources of selected POPs using both soil and vegetation as indicators in several Antarctic terrestrial ecosystems considering geographical variation, distance to the colonies and the use of different seabird species with different feeding ecology strategies.

\section{2 - Material and methods}

\section{1 - Sampling}

Since this is a two parts study, the present work was performed with the same samples used in the first one (Cipro et al., 2018a). Samples of lichen $(n=55)$, mosses $(n=58)$ and soils $(n=37)$, were collected in 13 locations within the South Shetlands Archipelago in the austral summers of 2013-14 and 2014-15 during cruises of the Brazilian Antarctic Programme and divided in two types: "colony" (within the colony itself for soil and within the colony or bordering such colony for vegetation) and "control" (at least 150m away from the respectively closest colony. Lichens and soil were collected in higher elevations than the colony, whereas mosses, due to their water-dependency, were collected in lower sites. All samples for POP analyses were collected with steel gear (spoons and tweezers) previously rinsed with n-hexane. All samples for stable isotope analysis (SIA) were collected with plastic gear (spoons and tweezers) firstly rinsed in an acid bath $\left(35 \mathrm{~mL} \mathrm{~L}^{-1}\right.$ nitric acid, $50 \mathrm{~mL} \mathrm{~L}^{-1}$ hydrochloric acid), then further rinsed with Milli-Q water. Soil samples were dug no deeper than $5 \mathrm{~cm}$. They were chosen at the field mainly by their availability, avoiding fresh faeces, which could mask the results for the formed ornithogenic soil. Samples were collected in triplicates whenever possible.

In some cases, samples were collected in more than one spot in each area of interest, which was described by the "main location" and "specific location" labels. Thus, the comparison between control and colony sites was made within the same specific location, when available, otherwise the closest control sample within the same main location was adopted. 
Once collected, samples for POPs analyses were stored in previously combusted aluminium foil and samples for SIA were stored in hermetically sealed plastic bags. They were frozen aboard $\left(-20^{\circ} \mathrm{C}\right)$ and kept frozen until arrival at the Marine Organic Chemistry Laboratory (LabQOM, University of São Paulo/Brazil), where all POPs analyses were performed and, also, where the SIA samples underwent lyophilisation. Vegetation species were identified by Prof. Jair Putzke (Universidade Federal do Pampa, São Gabriel, Brazil). SIA samples were then sent to the University of La Rochelle, France, where they were ground to a fine powder in a ceramic mortar before analyses. Soil samples were sifted (1 mm mesh) after freeze-drying in order to remove larger rock fragments and debris. Soil samples were not ground in any part of the process whatsoever in order to assure that only the granulometry of choice underwent analyses.

\section{2 - Analyses}

Analyses for POPs were performed for three classes of contaminants: polychlorinated biphenyls (PCBs), organochlorine pesticides (OCPs) and polybrominated diphenyl ethers (PBDEs).

Sample extraction followed a previously described method (Cipro et al., 2013), which resulted from an adaptation from literature (Macleod et al., 1986). Briefly, wet samples (10g for vegetation and colony soil, $20 \mathrm{~g}$ for control soil) were manually ground with anhydrous $\mathrm{Na}_{2} \mathrm{SO}_{4}$ and surrogate (PCB 103) was added before extraction in a Soxhlet apparatus for 8 hours with $80 \mathrm{ml}$ of $\mathrm{n}$-hexane and methylene chloride $(1: 1, \mathrm{v} / \mathrm{v})$. During the extraction, metallic copper was added to the flasks in order to retain sulphur. The extract was then concentrated to $1 \mathrm{ml}$ and cleaned up in a column filled (from top to bottom) with $16 \mathrm{~g}$ alumina and $8 \mathrm{~g}$ silica gel (both 5\% deactivated with water). A second rotoevaporation (up to $900 \square 1$ ) followed and finally, internal standard (100ng of TCMX, used to estimate surrogate recovery) was added to the purified extract prior to injection in the gas chromatograph. The same extract is used for all POPs analyses.

PCBs and PBDEs analyses were performed in an Agilent 6890 Plus attached to the MS 5973N Mass Selective Detector (GC/MS) in SIM (selective ion monitoring) mode, with a HP$5 \mathrm{MS}$ column $\quad(30 \mathrm{mx} 250 \square \mathrm{mx} 0.25 \square \mathrm{m}$, internally coated with $5 \%$ phenyl- $95 \%$ dimethylpolysiloxane). Helium was used as carrier gas at a constant flow $\left(1.1 \mathrm{~mL} \mathrm{~min}{ }^{-1}\right)$. Injection volume was $1 \square \mathrm{L}$ in splitless mode. Injector, interface and ion source operated at $280^{\circ} \mathrm{C}, 280^{\circ} \mathrm{C}$ and $300^{\circ} \mathrm{C}$ respectively. The oven ramp was programmed as follows: $75^{\circ} \mathrm{C}$ for 3 minutes, then rising at $15^{\circ} \mathrm{C} \min ^{-1}$ up to $150^{\circ} \mathrm{C}$, then rising at $2^{\circ} \mathrm{C} \min ^{-1}$ up to $260^{\circ} \mathrm{C}$, then rising 
at $20^{\circ} \mathrm{C} \mathrm{m^{-1 }}$ up to $300^{\circ} \mathrm{C}$ and remaining as so for 10 minutes for a total run time of 75 minutes. The analysed PCBs congeners were the IUPAC \# 8, 18, 28, 31, 33, 44, 49, 52, 56/60, 66, 70, $74,77,81,87,95,97,101,105,114,118,123,126,128,132,138,141,149,153,156,157$, $158,167,169,170,174,177,180,183,187,189,194,195,201,203,206$ and 209. In turn, the analysed PBDEs congeners were the IUPAC\# 28, 47, 99, 100, 153, 154 and 183.

OCPs analyses were run in a gas chromatograph equipped with an electron capture detector (GC-ECD, Agilent Technologies, model 6890N). Hydrogen was used as carrier gas at a constant pressure (13.0 psi). The injector operated in splitless mode and was kept at $300^{\circ} \mathrm{C}$. The capillary column used was the same HP-5MS. The detector operated at $320^{\circ} \mathrm{C}$ using $\mathrm{N}^{2}$ as makeup gas at a flow rate of $60 \mathrm{~mL} \mathrm{~min}^{-1}$. The oven was programmed as follows: starting at $60^{\circ} \mathrm{C}$, then rising at $5^{\circ} \mathrm{C} \min ^{-1}$ up to $150^{\circ} \mathrm{C}$, remaining as so for 6 minutes, then rising at $1^{\circ} \mathrm{C}$ $\min ^{-1}$ up to $200^{\circ} \mathrm{C}$, then rising at $18^{\circ} \mathrm{C} \mathrm{min}^{-1}$ up to $300^{\circ} \mathrm{C}$ remaining as so until a final run time of 90 minutes. The compounds analysed were the HCB (hexachlorobenzene), DDTs (Dichlorodiphenyltrichloroethane DDT, Dichlorodiphenyldichloroethylene DDE and Dichlorodiphenyldichloroethane DDD in op' and $\mathrm{pp}^{\prime}$ configurations), $\mathrm{HCHs}$ (Hexachlorocyclohexane in $\alpha, \beta, \gamma$, and $\delta$ isomers), chlordanes ( $\alpha$ - and $\gamma$-chlordane, oxichlordane, heptachlor, and heptachlor epoxide), mirex, metoxychlor, endosulfan and drins (aldrin, dieldrin, isodrin and endrin). OCPs quantifications were performed in GC-ECD only after confirmation in GC/MS, which decreased the number of detected compounds, as further discussed.

Method detection limits (MDLs) were calculated as being three times the standard deviation after seven blank replicates. Spiked matrices were recovered within the acceptance ranges (i.e. $40-130 \%$ for at least $80 \%$ of the spiked analytes) suggested by QA/QC standards (Wade and Cantillo, 1994). Method validation was performed using NIST SRM 1945. Blanks were included in every analytical batch (usually 10-12 samples) and all data were blanksubtracted. Average surrogate recovery was $93.27 \%$.

SIA was performed as described in the first part of this work (Cipro et al., 2018a), with the same restrictions, especially the decarbonation of soil samples. Due to the negligible lipid content and influence in the results verified during previous studies (Cipro et al., 2017a, 2011), samples have not undergone delipidation. Soil samples, however, have undergone a decarbonation procedure to avoid the interference of carbonates, which are depleted in ${ }^{13} \mathrm{C}$ and could represent a bias in data interpretation. The decarbonation was as follows: up to $100 \mathrm{mg}$ of ground sample were put in a glass vial, $1 \mathrm{~mL}$ of $\mathrm{HCl} 0.1 \mathrm{~N}$ were added and the vial was placed 
in a microwave bath, observing bubble formation as an indicator of carbonates digestion. After one minute, $100 \mu \mathrm{l}$ of the same acid was added to verify that no more bubble formation was shown. If that was the case, this first step was repeated many times as needed. Next, the vials were put in a $60^{\circ} \mathrm{C}$ dry bath (Techne) coupled to an evaporation system consisting of tubes gently blowing filtered analytical quality compressed air into the vials overnight in order to evaporate the liquid acidic phase. The following day, samples were recovered with $1 \mathrm{~mL}$ of Milli-Q water, homogenised in a microwave bath for 1 minute, frozen and finally lyophilised.

SIA themselves were performed as follows: an aliquot of ground prepared sample (0.8 up to $1.5 \mathrm{mg}$ for vegetation, 1.5 to $8 \mathrm{mg}$ for colony soil, 8 to $16 \mathrm{mg}$ for control soil) was encapsulated in tin cups and injected in a Thermo Scientific Delta V AdvantageConFlo IV interface (NoBlank and SmartEA) coupled to a Thermo ScientificFlash EA1112 Elemental Analyser. Pee Dee Belemnite and atmospheric nitrogen were used as standards for calculation of $\delta^{13} \mathrm{C}$ and $\delta^{15} \mathrm{~N}$, respectively. Based on replicate measurements of internal laboratory standards, experimental precision is of $\pm 0.15 \%$ and $\pm 0.20 \%$ for $\delta^{13} \mathrm{C}$ and $\delta^{15} \mathrm{~N}$, respectively.

\section{3 - Statistics}

Statistics were performed using Microsoft Excel, Minitab 18 and Statsoft Statistica 10 and 13. Before analyses, data were checked for normality of distribution and homogeneity of variances using Shapiro-Wilk and Brown-Forsythe tests, respectively. Statistically significant results are set at $\square=0.05$ unless stated otherwise. Differences of colony and control datasets were assessed by means of t-tests and Pearson/Spearman correlations are chosen due to their linear/monotonic nature and not necessarily to parametric/non-parametric analyses.

Normal distribution and log-link function generalized linear models (GLM) were built as follows: POPs concentrations as the dependent variable; matrix, main location, specific location, colony species and matrix species as categorical factors; $\delta^{13} \mathrm{C}, \delta^{15} \mathrm{~N}, \% \mathrm{C}$ and $\% \mathrm{~N}$ as continuous predictors. Biologically relevant models were constructed incorporating the different variables and their interactions taking the care of removing continuous variables that were significantly correlated before model building in each dataset and its subsets as well. Model selection was based on Akaïke's Information Criteria adjusted for small sample sizes (AICc). The model with the lowest AICc value was considered to be the most accurate. Models with AICc values differing by less than 2 have a similar level of support in the data, and the model including the least number of parameters can be regarded as the most accurate, according to the principle of parsimony (Burnham and Anderson, 2002). Overall model support was 
assessed using Akaike weights ( $\left.\mathrm{w}_{\mathrm{i}}\right)$, following Johnson and Omland (2004). Residual ( $\mathrm{R}^{2} \mathrm{adj}$ ) analyses should be restricted to description and not be used in model selection (Burnham and Anderson, 2002). Only models with AICc values differing by less than 10 are presented.

\section{3 - Results and discussion}

The most present compounds in both vegetation and soil samples were HCB and PCBs. None of the PBDEs nor HCHs has overcome the MDL in none of the samples. Due to a methodology modification regarding a previous work (direct GC-ECD quantification in Cipro et al., 2011 versus ECD quantification after GC-MS confirmation in the present study), the remaining POPs could be detected and quantified in only a small fraction of the samples and unfortunately do not allow further discussion: chlordanes were present in detectable amounts in only 5 samples, DDTs in 4, Drins in 4 and mirex in 5 from a total of 150 samples. Therefore, Table 1 presents the data for HCB, PCBs, SIA and centesimal composition for $\mathrm{C}$ and $\mathrm{N}$. Nevertheless, the full dataset is present as supplementary material (Table S1).

Regarding the concentrations presented in Table 1, some patterns appear. In a general way, for control samples, lichens and mosses presented similar PCBs concentrations and both were one order of magnitude above those found in control soil. Considering colony samples, the pattern is somewhat similar: lichens presenting concentrations slightly higher than mosses and both one order of magnitude higher than soil in average again. Therefore, the main difference in PCBs distribution between colony and control samples would be a relative increase in lichens concentration in colony samples, meaning that, proportionally, most of the input derived from the colony ends up absorbed by this matrix, possibly by volatilisation and/or resuspension. $\mathrm{HCB}$, in turn, presented mean concentrations in control samples in mosses around $50 \%$ higher than those found in lichens; which in turn presented values that were double those found in soil, all of them within the same order of magnitude. In colony samples, however, HCB presented overall concentrations in soil samples one order of magnitude above those found in mosses (with the exception of P. papua from Hannah Point likely due to some local effect such as water percolation); and mosses, on the other hand, presented concentrations one order of magnitude higher than lichens. This leads to the conclusion that firstly, HCB is proportionally more excreted than PCBs. Moreover, HCB dominated seabird profiles are reported by literature (Carravieri et al., 2014) and, in this regard, similar data from chicks (Carravieri et al., 2017) evidentiate this phenomenon since most of their POPs burden comes from what is not accumulated by the mother. In addition to that, several previous works 
demonstrate proportionally lighter profiles in excreta (Roosens et al., 2007; Rudolph et al., 2016). Another consideration is yet to be made: the very high levels found in the $P$. atriceps soil colony samples is likely due to the fact that they form dense colonies in high and dry spots, so very little water percolation occurs when compared to penguin colonies for instance.

Secondly, volatilisation and/or resuspension play a proportionally lesser role in this case when compared to PCBs, likely due to a higher water solubility (therefore a lower $\mathrm{K}_{\mathrm{ow}}$ of $\mathrm{HCB}$ than most PCBs) of the former regarding the latter and also due to a higher water dependency of mosses compared to lichens (see Cipro et al., 2011). This interpretation, however, hangs on the lack of data concerning the absorption mechanism of POPs in mosses. Simple diffusion can explain our results, but there is probably some non-linearity in the absorption process. The results for the even more water soluble $\mathrm{HCHs}$ could enlighten this issue, but unfortunately they have remained under the method detection level.

In order to go deeper in the understanding of POPs occurrence and dynamics, correlation analyses and PCA have been performed. Spearman correlation results are presented in Table 2, whereas PCA is presented as supplementary material (Fig. S1).

Lichen in control sites presented two significant correlations for POPs. Firstly, a positive one of PCBs and $\% \mathrm{~N}$, meaning that a common source is possibly shared, likely atmospheric deposition from long range transport (Montone et al., 2005, 2003), even if the role of colonies as sources via resuspension/volatilisation cannot be discarded at this point. A negative correlation for $\mathrm{HCB}$ and \% $\mathrm{C}$ was also found for this subgroup, leading to two possible, nonmutually excluding hypotheses: the range of the resuspended/volatilised HCB from sources is greater than that of organic carbon and also that some organic matter decomposition process might play a role as hypothesized in the previous work (Cipro et al., 2018a). This would mean that HCB might be liberated in the atmosphere but the organic carbon might be trapped by some previous step of its biogeochemical cycle. Lichen in colony sites, however, presented several significant correlations. PCBs correlated positively with $\% \mathrm{C}$ and negatively with $\delta^{15} \mathrm{~N}$ whereas $\mathrm{HCB}$ presented the same ones and also a negative correlation with $\% \mathrm{~N}$. The first two ones can be explained by the decomposition of the animal derived organic matter. The kinetic fractionations during the decomposition of deposited urea and uric acid lead to the formation of starkly ${ }^{15} \mathrm{~N}$-depleted highly volatile ammonia whereas the remaining ammonium, much less volatile, is conversely ${ }^{15} \mathrm{~N}$-enriched (Heaton, 1986). Therefore it results that vegetation around the excrement zone are more exposed to ${ }^{15} \mathrm{~N}$-enriched inorganic nitrogen whereas upland sites are more exposed to ${ }^{15} \mathrm{~N}$-depleted nitrogen (Cipro et al., 2018a, 2011), as indicated by the results 
found. Moreover, and as a consequence of the previous statement, animal-derived nitrogen uptake is associated with large $\delta^{15} \mathrm{~N}$ ranges, with typical values ranging between 6 and 26\%o (e.g. Cipro et al., 2011; Cocks et al., 1998; Erskine et al., 1998; Mizutani and Wada, 1988). The negative correlation between $\mathrm{HCB}$ and $\% \mathrm{~N}$ is likely explained in an analogous manner to the previous negative correlation between this contaminant and $\% \mathrm{C}$ in control sites, i.e. the contaminant might be released to the atmosphere but this time, we hypothesise that the nitrogen might be trapped by some previous step of its biogeochemical cycle. Some of these same patterns were found for SIA and trace elements, particularly the more volatile $\mathrm{Hg}$ in the previous study (Cipro et al., 2018a).

Moss in control sites presented no significant correlation for any of the contaminants. In colony sites, however, a negative correlation between PCBs and $\% \mathrm{~N}$ and a positive one between $\mathrm{HCB}$ and $\delta^{13} \mathrm{C}$ were detected. The first one, besides the previously discussed occurrence in lichens, was also found in several of the trace elements $(\mathrm{Co}, \mathrm{Fe}, \mathrm{Mn}, \mathrm{Ni}, \mathrm{Pb}$, and V) analysed in the first part of the study (Cipro et al., 2018a). Some of these, particularly Mn and $\mathrm{Pb}$, have already been reported with comparatively higher concentrations in Gentoo penguins (Pygoscelis papua) faeces (Celis et al., 2015) and, therefore, might confirm the role of colonies as secondary sources for PCBs in an analogous manner. The correlation between $\mathrm{HCB}$ and $\delta^{13} \mathrm{C}$ is at a first glance, somewhat contrary to the previous literature that suggests lower $\delta^{13} \mathrm{C}$ values are related to moister habitats and marine influence (Cipro et al., 2011; Huiskes et al., 2006; Lee et al., 2009), since mosses are more water dependant than lichens, negative correlations were to be expected. However, this intra-group correlation means that the samples in dryer locations are more exposed to HCB, which is consistent with its comparatively higher volatility.

Soil presented no significant correlations for any of the contaminants in the present study neither for control nor for colony sites.

PCA results (Fig S1, supplementary material) reinforce the previously discussed correlations on the subsets of samples. Nevertheless, when the broader data is taken into account two interesting trends show up: the pattern for all lichen samples taken together resembles closely that for its control sites, whereas the pattern for all moss samples taken together resembles even more closely that for its colony sites. This likely means that the mechanisms for POPs exposure in control sites are more representative for the entirety of the lichens, i.e., long-range atmospheric transport is probably the major force in this case. Mosses, on the other hand, that presented patterns for the whole dataset even closer to the ones regarding colony 
samples, allow an analogous interpretation: the input via water from colony percolation, as hypothesised in previous works (Cipro et al., 2018b, 2011) would be the more relevant specific exposure phenomenon. This similarity does not occur for soil samples, likely meaning that specific mechanisms at the local scale regulate each one of the situations.

\section{1 - PCBs chlorination level}

The average relative chlorination number of the PBCs found in the matrixes is shown in Figure 1.

In all cases, the profile from the control sites was lighter than the one from colony sites, meaning that lower molecular weight congeners are more subject to undergo a transport process via resuspension/volatilisation. Yet, the results show congeners with 5 and 4 chlorine substitutions as the most frequent, in this order, except for lichen from control sites, when this order was inverted; These results reinforce the hypothesis that the exposure to PCBs only occur through atmospheric deposition due to the lack of a true root system to absorb compounds from the substratum (Liu et al., 2010).

Moreover, the comparison with the data from King George Island only, in a study in which the samples were collected further away from any interference of seabird colonies (Cipro et al., 2011), shows PCBs profiles in vegetation even lighter than the ones from the present study, reinforcing the fact that heavier congeners are less mobile regarding both primary (see von Waldow et al., 2010) and secondary sources: as one moves away from colonies, the profiles become proportionally lighter due to a lesser input of heavier congeners and also from a higher input of lighter ones. Because heavier congeners are more environmentally persistent (Fuoco and Ceccarini, 2001), this has also to be taken into account when considering this proportionally heavier profiles from colonies. The overall profiles for both vegetation subgroups come in close agreement with previous literature, particularly for snow samples (Cipro et al., 2017b), subject to a much similar input mechanism from the atmosphere.

Soil samples, however, concentrated roughly $90 \%$ of their congeners in tetra and penta chlorinated congeners, with the latter representing around $75 \%$. This distribution is corroborated by literature (Roosens et al., 2007) where pentachlorinated congeners also prevailed. This distribution is due to the fact that most of the more persistent PCBs sit in the interval from 4 to 6 chlorine substitutions. As the authors state, the profiles were dominated by comparatively heavier congeners indicating penguins as the main source rather than long range atmospheric deposition, in which case a lighter profile would be expected . 


\section{2 - Factors influencing PCBs and HCB concentrations}

In order to evaluate the relative importance of the categorical variables (main location, specific location, colony species and matrix species), GLM models were built and model selection was based upon AICc as previously explained. Results are presented in Table 3.

No model building was possible for the soil colony subgroup neither for PCBs nor for HCB due to the number of samples under the method detection limit paired with the other variables being taken into account.

The results come partially in agreement with the first part of the study. In a general way, models with less factors were more present among the most accurate in the present study, with models presenting only one factor being the most accurate in almost half of the cases. Specific Location and $\% \mathrm{C}$ were the most present factor in the chosen models, whereas for trace elements Specific Location and Matrix Species seem to play a more important role. This means that for POPs, due to the comparatively higher tendency to volatilise/resuspend in regard to trace elements, the organic matter concentration, Matrix Species seem to have a less important role than the sheer quantity of organic matter, except for lichens. This also comes in agreement with previous works suggesting that a migration into the liquid phase is likely to precede the absorption of POPs by more water-dependent organisms (Cipro et al., 2018b, 2011) when compared to lichens that will not interact with the substratum and absorb contaminants directly from the atmosphere (Yogui and Sericano, 2008).

\section{3 - Control sites versus colony sites}

Firstly, Tukey HSD/ANOVA tests were performed in order to understand whether some control sites with apparently abnormal concentrations were really not grouped with their counterparts, confirming some hypothesised local sources other than the colonies. Even with apparent huge disparities among the data subsets, the only case when the homogenous groups after the post-hoc test indicated a separation was for PCBs in lichens from Deception Island. Indeed, this site presented the highest concentrations for PCBs from control sites in both lichen and mosses, but was the least contaminated control soil dataset. This pattern, however, is not repeated for HCB. These results for vegetation are much higher than those found in previous literature (Cabrerizo et al., 2012), which presented levels of PCBs in locations closer to ancient 
stations (such as our location) higher than those found in the vicinity of more recent ones. This means that ancient contamination and eventual spillages might have not yet been completely revolatilised in a homogenous manner as the authors hypothesise (Cabrerizo et al., 2012), at least not in our area of sampling within Deception Island, different from theirs. In other words, if a seabird colony can act as a relevant secondary source, an abandoned station also can. Yet, we hereby hypothesise another factor, which is the local volcanic activity via fumaroles, increasing the temperature in some zones, favouring the revolatilisation of PCBs and thus, the exposure of vegetation to them.

Following, the results for the t-tests of colony sites compared to the closest control site are presented in Table 4.

Lichens presented significant differences in POPs concentrations between control and colony sites in two occasions: for PCBs from a chinstrap penguin Pygoscelis antarcticus colony from Half Moon Island and for HCB from an Antarctic tern Sterna vittata colony from Penguin Island. In both cases there has been also a significant difference in the organic matter content, corroborating the statement that the role of nutrient source is not separated from the role of contaminants source.

Mosses, on the other hand, did not present any significant difference in POPs concentrations. Despite some huge differences found, they were not statistically significant likely due to the relatively high standard deviation in these cases. Moreover, in some cases the control sites did not overcome the method detection limits and the proper comparison was not possible.

Soil samples, however, presented significant differences in one occasion: Adélie penguin Pygoscelis adeliae colony samples from Turret Point, King George Island, in similar conditions to the ones previously discussed for lichens: significant differences in organic matter content and also SIA indicating that the nutrient and contaminants sources are indeed the same one. Again, the same issues are repeated: some samples presented elevated standard deviations suggesting higher levels than the control sites, but not in a statistically significant manner.

Comparing the matrixes among them and also with the first part of the study (Cipro et al., 2018a), some trends seem clear. Firstly, the accumulation of contaminants is correlated to the contents of organic matter and SIA results, but in different ways. In lichens, $\% \mathrm{~N}$ seems to be the common factor for the most contaminated samples, whereas in mosses the response is somewhat mixed but $\delta^{13} \mathrm{C}$ seems to correlate in the cases when differences from control to 
colony sites were the highest for both POPs and trace elements. Soil, in turn, presented \%C clearly as the common factor for the highest differences in both studies. However, the interpretation for these specific cases is rather limited and has to be taken with caution. However, it is not possible to affirm that because one proxy correlates to a significant difference, then a high level for such proxy will imply a significant difference in POPs levels between control and colony sites.

All of that considered, a broader, more robust approach for interpreting both POPs and trace elements datasets is clearly given by AICc.

\section{4 - Conclusions}

Seabird colonies act as secondary sources of PCBs and likely of HCB as well. The role of colonies as secondary HCB source is not demonstrated as clear as for PCBs, particularly for lichens, likely due to two reasons. Given the comparatively higher HCB volatility, the $150 \mathrm{~m}$ distance adopted in order to qualify a site as control might not be fully adequate for this analysis and could be reviewed in the future. The second reason is that some control sites have again presented somewhat high concentrations likely due to local sources other than the colonies themselves. For the other matrixes, especially soil, the role of such colonies as relevant secondary seems clearly demonstrated. Soil seemed the most adequate matrix to study this phenomenon and further more detailed research is needed on the vegetation due to specific uptake mechanisms that could not be deeply taken into account, particularly for lichens. Finally, future studies on population parameters and dynamics could clarify some of the interspecific differences found.

\section{Acknowledgements}

Again, the authors would like to acknowledge the financing organisms in the University of La Rochelle: CPER (Contrat de Plan État-Région) and FASEP (Fonds d'étude et d'aide au secteur privé). C.V.Z. Cipro received scholarships from FAPESP (São Paulo Research Foundation, Brazil. Grant \#2014/15989-0 and grant \#2015/07209-8). M. V. Petry and R. C. Montone received funding from INCT-APA (Instituto Nacional de Ciência e Tecnologia Antártico de Pesquisas Ambientais) (CNPq Process n574018/2008-5), FAPERJ (E26/170.023/2008) and were supported by the SECIRM, MMA and MCTI. The IUF (Institut Universitaire de France) is acknowledged for its support to Paco Bustamante as a senior 
member. G. Guillou and B. Lebreton from the "Plateforme Analyses Isotopiques" of LIENSs are also to be thanked for their assistance during SIA analyses. Finally, many thanks are dedicated to everyone involved in the fieldwork.

\section{References}

Anderson, W.B., Polis, G. a., 1999. Nutrient fluxes from water to land: seabirds affect plant nutrient status on Gulf of California islands. Oecologia 118, 324-332. doi:10.1007/s004420050733

Ballance, L.T., Ainley, D.G., Ballard, G., Barton, K., 2009. An energetic correlate between colony size and foraging effort in seabirds, an example of the adélie penguin pygoscelis adeliae. J. Avian Biol. 40, 279-288. doi:10.1111/j.1600-048X.2008.04538.x

Blais, J.M., 2005. Arctic Seabirds Transport Marine-Derived Contaminants. Science (80-. ). 309, 445-445. doi:10.1126/science.1112658

Blais, J.M., Macdonald, R.W., Mackay, D., Webster, E., Harvey, C., Smol, J.P., 2007. Biologically Mediated Transport of Contaminants to Aquatic Systems Critical Review Biologically Mediated Transport of Contaminants to Aquatic Systems 41, 1075-1084. doi:10.1021/es061314a

Borghini, F., Grimalt, J.O., Sanchez-Hernandez, J.C., Bargagli, R., 2005. Organochlorine pollutants in soils and mosses from Victoria Land (Antarctica). Chemosphere 58, 271-8. doi:10.1016/j.chemosphere.2004.07.025

Brasso, R.L., Polito, M.J., Lynch, H.J., Naveen, R., Emslie, S.D., 2012. Penguin eggshell membranes reflect homogeneity of mercury in the marine food web surrounding the Antarctic Peninsula. Sci. Total Environ. 439, 165-71. doi:10.1016/j.scitotenv.2012.09.028

Burnham, K.P., Anderson, D.R., 2002. Model Selection and Multimodel Inference, 2nd ed. Springer.

Cabrerizo, A., Dachs, J., Barceló, D., Jones, K.C., 2012. Influence of organic matter content and human activities on the occurrence of organic pollutants in antarctic soils, lichens, grass, and mosses. Environ. Sci. Technol. 46, 1396-1405. doi:10.1021/es203425b

Carravieri, A., Bustamante, P., Tartu, S., Meillère, A., Labadie, P., Budzinski, H., Peluhet, L., Barbraud, C., Weimerskirch, H., Chastel, O., Cherel, Y., 2014. Wandering Albatrosses 
Document Latitudinal Variations in the Transfer of Persistent Organic Pollutants and Mercury to Southern Ocean Predators. Environ. Sci. Technol. 48, 14746-14755. doi:10.1021/es504601m

Carravieri, A., Cherel, Y., Brault-Favrou, M., Churlaud, C., Peluhet, L., Labadie, P., Budzinski, H., Chastel, O., Bustamante, P., 2017. From Antarctica to the subtropics: Contrasted geographical concentrations of selenium, mercury, and persistent organic pollutants in skua chicks (Catharacta spp.). Environ. Pollut. 228, 464-473. doi:10.1016/j.envpol.2017.05.053

Celis, J.E., Barra, R., Espejo, W., González-Acuña, D., Jara, S., 2015. Trace Element Concentrations in Biotic Matrices of Gentoo Penguins (Pygoscelis Papua) and Coastal Soils from Different Locations of the Antarctic Peninsula. Water. Air. Soil Pollut. 226. doi:10.1007/s11270-014-2266-5

Cipro, C.V.Z., Bustamante, P., Petry, M.V., Montone, R.C., 2018a. Seabird colonies as relevant sources of pollutants in Antarctic ecosystems: Part 1 - Trace elements. Chemosphere 204, 535-547. doi:10.1016/j.chemosphere.2018.02.048

Cipro, C.V.Z., Cherel, Y., Bocher, P., Caurant, F., Miramand, P., Bustamante, P., 2018b. Trace elements in invertebrates and fish from Kerguelen waters, southern Indian Ocean. Polar Biol. 41, 175-191. doi:10.1007/s00300-017-2180-6

Cipro, C.V.Z., Colabuono, F.I., Taniguchi, S., Montone, R.C., 2013. Persistent organic pollutants in bird, fish and invertebrate samples from King George Island, Antarctica. Antarct. Sci. 25. doi:10.1017/S0954102012001149

Cipro, C.V.Z., Montone, R.C., Bustamante, P., 2017a. Mercury in the ecosystem of Admiralty Bay, King George Island, Antarctica: Occurrence and trophic distribution. Mar. Pollut. Bull. 114. doi:10.1016/j.marpolbul.2016.09.024

Cipro, C.V.Z., Taniguchi, S., Montone, R.C., 2017b. Organic Pollutants in Snow and Seasonal Melting Water from King George Island, Antarctica. Water. Air. Soil Pollut. 228. doi:10.1007/s11270-017-3325-5

Cipro, C.V.Z., Yogui, G.T., Bustamante, P., Taniguchi, S., Sericano, J.L., Montone, R.C., 2011. Organic pollutants and their correlation with stable isotopes in vegetation from King George Island, Antarctica. Chemosphere 85, 393-8. doi:10.1016/j.chemosphere.2011.07.047 
Cocks, M.P., Balfour, D. a., Stock, W.D., 1998. On the uptake of ornithogenic products by plants on the inland mountains of Dronning Maud Land, Antarctica, using stable isotopes. Polar Biol. 20, 107-111. doi:10.1007/s003000050283

Emslie, S.D., Polito, M.J., Brasso, R., Patterson, W.P., Sun, L., 2014. Ornithogenic soils and the paleoecology of pygoscelid penguins in antarctica. Quat. Int. 352, 4-15. doi:10.1016/j.quaint.2014.07.031

Erskine, P.D., Bergstrom, D.M., Schmidt, S., Stewart, G.R., Tweedie, C.E., Shaw, J.D., 1998. Subantarctic Macquarie Island - a model ecosystem for studying animal-derived nitrogen sources using $15 \mathrm{~N}$ natural abundance. Oecologia 117, 187-193. doi:10.1007/s004420050647

Fuoco, R., Ceccarini, A., 2001. Polychlorobiphenyls in Antarctic matrices. Environ. Contam. Antarct. a Chall. Anal. Chem. 169, 237-274.

Heaton, T.H.E., 1986. Isotopic studies of nitrogen pollution in the hydrosphere and atmosphere: a review. Chem. Geol. 59, 87-102.

Huiskes, a. H.L., Boschker, H.T.S., Lud, D., Moerdijk-Poortvliet, T.C.W., 2006. Stable isotope ratios as a tool for assessing changes in carbon and nutrient sources in Antarctic terrestrial ecosystems. Plant Ecol. doi:10.1007/s11258-005-9032-0

Johnson, J.B., Omland, K.S., 2004. Model selection in ecology and evolution. Trends Ecol. Evol. 19, 101-8. doi:10.1016/j.tree.2003.10.013

Lee, Y. Il, Lim, H.S., Yoon, H. Il, 2009. Carbon and nitrogen isotope composition of vegetation on King George Island, maritime Antarctic. Polar Biol. 32, 1607-1615. doi:10.1007/s00300-009-0659-5

Liu, X.-Y., Xiao, H.-Y., Liu, C.-Q., Li, Y.-Y., Xiao, H.-W., Wang, Y.-L., 2010. Response of stable carbon isotope in epilithic mosses to atmospheric nitrogen deposition. Environ. Pollut. 158, 2273-81. doi:10.1016/j.envpol.2010.02.005

Liu, X., Li, H., Sun, L., Yin, X., Zhao, S., Wang, Y., 2006. $\delta 13 \mathrm{C}$ and $\delta 15 \mathrm{~N}$ in the ornithogenic sediments from the Antarctic maritime as palaeoecological proxies during the past 2000 yr. Earth Planet. Sci. Lett. 243, 424-438. doi:10.1016/j.epsl.2006.01.018

Loganathan, B.G., Kannan, K., 1991. Time perspectives of organochlorine contamination in the global environment. Mar. Pollut. Bull. 22, 582-584. doi:10.1016/0025326X(91)90244-M 
Macleod, M., Brown, D., Friedman, A., Burrows, D., Maynes, O., Pearce, R., Wigren, C., Bogar, R., 1986. Standard Analytical Procedures of the NOAA National Analytical Facility, 1985-1986., in: US. Department of Commerce, N.N.T.M.N.F. (Ed.), Extractable Toxic Organic Components, Second Edition.

Mizutani, H., Wada, E., 1988. Nitrogen and carbon isotope ratios in seabird rookeries and their ecological implications. Ecology 69, 340-349.

Montone, R.C., Taniguchi, S., Boian, C., Weber, R.R., 2005. PCBs and chlorinated pesticides (DDTs, HCHs and HCB) in the atmosphere of the southwest Atlantic and Antarctic oceans. Mar. Pollut. Bull. 50, 778-82. doi:10.1016/j.marpolbul.2005.03.002

Montone, R.C., Taniguchi, S., Weber, R.R., 2003. PCBs in the atmosphere of King George Island, Antarctica. Sci. Total Environ. 308, 167-73. doi:10.1016/S0048-9697(02)006496

Negoita, T.G., Covaci, A., Gheorghe, A., Schepens, P., 2003. Distribution of polychlorinated biphenyls (PCBs) and organochlorine pesticides in soils from the East Antarctic coast. J. Environ. Monit. 5, 281-286. doi:10.1039/b300555k

Outridge, P.M., Goodsite, M.E., Bennike, O., Rausch, N., Shotyk, W., 2016. Seabird transfer of nutrients and trace elements from the north water polynya to land during the midholocene warm period, carey islands, northwest Greenland. Arctic 69, 253-265. doi:10.14430/arctic4577

Roosens, L., Van Den Brink, N., Riddle, M., Blust, R., Neels, H., Covaci, A., 2007. Penguin colonies as secondary sources of contamination with persistent organic pollutants. J. Environ. Monit. 9, 822-5. doi:10.1039/b708103k

Rudolph, I., Chiang, G., Galbán-Malagón, C., Mendoza, R., Martinez, M., Gonzalez, C., Becerra, J., Servos, M.R., Munkittrick, K.R., Barra, R., 2016. Persistent organic pollutants and porphyrins biomarkers in penguin faeces from Kopaitic Island and Antarctic Peninsula. Sci. Total Environ. 573, 1390-1396. doi:10.1016/j.scitotenv.2016.07.091

Smykla, J., Wołek, J., Barcikowski, A., 2007. Zonation of Vegetation Related to Penguin Rookeries on King George Island, Maritime Antarctic. Arctic, Antarct. Alp. Res. 39, 143-151. doi:10.1657/1523-043

Tarcau, D., Cucu-Man, S., Boruvkova, J., Klanova, J., Covaci, A., 2013. Organochlorine 
pesticides in soil, moss and tree-bark from North-Eastern Romania. Sci. Total Environ. 456-457, 317-24. doi:10.1016/j.scitotenv.2013.03.103

Tatur, a., Myrcha, A., Niegodzisz, J., 1997. Formation of abandoned penguin rookery ecosystems in the maritime Antarctic. Polar Biol. 17, 405-417. doi:10.1007/s003000050135

von Waldow, H., Macleod, M., Scheringer, M., Hungerbühler, K., 2010. Quantifying remoteness from emission sources of persistent organic pollutants on a global scale. Environ. Sci. Technol. 44, 2791-6. doi:10.1021/es9030694

Wade, T.L., Cantillo, A.Y., 1994. Use of standards and reference materials in the measurement of chlorinated hydrocarbon residues. Chem. Work. NOAA Tech. Memo. NOS ORCA 77, 59.

Yogui, G.T., Sericano, J.L., 2008. Polybrominated diphenyl ether flame retardants in lichens and mosses from King George Island, maritime Antarctica. Chemosphere 73, 1589-93. doi:10.1016/j.chemosphere.2008.08.035 
Table 1. Mean \pm standard deviation results for POPs concentrations in $\left(\mathrm{ng} \mathrm{g}^{-1} \mathrm{ww}\right)$, SIA (\%o) and C and $\mathrm{N}$ content (\%) separated by location, colony species and matrix species. Colony species marked with an * indicate very sparse colonies.

\begin{tabular}{|c|c|c|c|c|c|c|c|c|c|c|}
\hline Main Location & Specific Location & Colony species & Matrix Species & $n$ & $\Sigma$ PCBs & $\mathrm{HCB}$ & $\delta^{13} \mathrm{C}$ & $\% \mathrm{C}$ & $\delta^{15} \mathrm{~N}$ & $\% \mathrm{~N}$ \\
\hline Deception Island & Deception Island & Control & Usnea antarctica & 3 & $65.5 \pm 2.58$ & $6.75 \pm 2.07$ & $-22.175 \pm 3.69$ & $30.8 \pm 16.7$ & $-0.680 \pm 11.0$ & $2.13 \pm 1.22$ \\
\hline \multirow{2}{*}{ Half Moon } & \multirow{2}{*}{ Half Moon } & Control & Usnea aurantiaco-ater & 3 & $11.5 \pm 14.8$ & $1.43 \pm 0.613$ & $-22.300 \pm 0.136$ & $41.7 \pm 0.264$ & $-5.730 \pm 0.947$ & $0.960 \pm 0.060$ \\
\hline & & Pygoscelis antarcticus & Ramalina terebrata & 3 & $60.4 \pm 1.58$ & 3.72 & $-23.940 \pm 0.840$ & $41.3 \pm 0.326$ & $-0.343 \pm 1.53$ & $2.21 \pm 0.466$ \\
\hline \multirow{10}{*}{ KGI } & Cape Vauréal & | Macronectes giganteus & Usnea antarctica & 3 & $5.65 \pm 0.843$ & $5.07 \pm 1.25$ & $-21.960 \pm 0.701$ & $40.1 \pm 0.895$ & $-0.028 \pm 0.793$ & $0.668 \pm 0.025$ \\
\hline & Ferraz & Control & Usnea aurantiaco-ater & 3 & $5.04 \pm 4.31$ & $1.82 \pm 0.187$ & $-20.750 \pm 0.125$ & $39.4 \pm 1.67$ & $-6.612 \pm 4.83$ & $0.341 \pm 0.046$ \\
\hline & Punta Hennequin & Catharacta $s p^{*}$ & Usnea antarctica & 3 & $5.85 \pm 3.87$ & & $-23.175 \pm 0.403$ & $40.4 \pm 1.28$ & $0.250 \pm 1.35$ & $1.64 \pm 0.464$ \\
\hline & Stenhouse & Larus dominicanus* & Usnea antarctica & 3 & $10.5 \pm 5.38$ & $6.02 \pm 2.37$ & $-22.395 \pm 0.864$ & $40.6 \pm 0.886$ & $-5.904 \pm 0.814$ & $0.526 \pm 0.065$ \\
\hline & \multirow{5}{*}{ Turret Point } & \multirow{3}{*}{ Control } & Ramalina terebrata & 3 & $6.44 \pm 4.69$ & & $-24.366 \pm 0.191$ & $40.5 \pm 0.774$ & $0.852 \pm 0.922$ & $1.67 \pm 0.161$ \\
\hline & & & Usnea antarctica & 3 & $4.53 \pm 2.96$ & $7.14 \pm 7.75$ & $-22.702 \pm 0.223$ & $40.3 \pm 1.21$ & $-3.155 \pm 0.555$ & $1.40 \pm 0.311$ \\
\hline & & & Usnea aurantiaco-ater & 3 & $10.8 \pm 2.97$ & $7.48 \pm 0.321$ & $-21.486 \pm 0.297$ & $39.9 \pm 0.520$ & $-5.875 \pm 0.599$ & $1.44 \pm 0.076$ \\
\hline & & Phalacrocorax atriceps & Ramalina terebrata & 3 & $1.72 \pm 1.38$ & $2.53 \pm 0.413$ & $-22.880 \pm 0.152$ & $38.5 \pm 0.522$ & $1.25 \pm 0.420$ & $1.50 \pm 0.205$ \\
\hline & & Pygoscelis adeliae & Usnea antarctica & 3 & $4.10 \pm 0.529$ & $3.55 \pm 0.042$ & $-23.339 \pm 0.102$ & $38.4 \pm 1.39$ & $-1.594 \pm 1.83$ & $1.42 \pm 0.478$ \\
\hline & Yellow Point & Control & | Usnea aurantiaco-ater & 1 & 1.87 & & -22.066 & 39.0 & -1.949 & 1.34 \\
\hline \multirow{3}{*}{ Livingston } & \multirow{3}{*}{ Hannah Point } & \multirow[b]{2}{*}{ Macronectes giganteus } & Ramalina terebrata & 2 & $4.65 \pm 1.56$ & 1.79 & $-24.050 \pm 0.137$ & $42.1 \pm 3.29$ & $-1.693 \pm 7.07$ & $1.85 \pm 0.662$ \\
\hline & & & $\begin{array}{l}\text { Turgidiusculum } \\
\text { complicatulum }\end{array}$ & 1 & 0.710 & 0.845 & -16.170 & 33.7 & 9.78 & 4.18 \\
\hline & & Pygoscelis papua & Ramalina terebrata & 3 & $2.86 \pm 1.64$ & $3.58 \pm 1.98$ & $-22.731 \pm 0.333$ & $40.2 \pm 1.04$ & $11.2 \pm 0.588$ & $2.02 \pm 0.071$ \\
\hline \multirow[t]{2}{*}{ Nelson Island } & \multirow[t]{2}{*}{ Nelson Island } & Daption capense $e^{* *}$ & | Usnea aurantiaco-ater & 3 & $2.39 \pm 0.433$ & $3.42 \pm 0.442$ & $-22.837 \pm 0.525$ & $41.5 \pm 2.18$ & $5.04 \pm 6.30$ & $1.12 \pm 0.171$ \\
\hline & & Control & Usnea aurantiaco-ater & 3 & $2.91 \pm 0.560$ & $2.55 \pm 0.356$ & $-22.184 \pm 0.745$ & $41.3 \pm 0.328$ & $-5.393 \pm 0.864$ & $0.869 \pm 0.151$ \\
\hline \multirow[t]{2}{*}{ Penguin Island } & \multirow[t]{2}{*}{ Penguin Island } & \multirow[b]{2}{*}{ Sterna vittata } & Ramalina terebrata & 3 & $3.08 \pm$ & $1.59 \pm$ & $-24.832 \pm$ & $34.1 \pm$ & $-2.575 \pm 0.336$ & $0.923 \pm 0.022$ \\
\hline & & & Usnea aurantiaco-ater & 3 & $3.58 \pm 0.828$ & $4.70 \pm 0.576$ & $-23.389 \pm 0.332$ & $39.2 \pm 0.299$ & $-7.417 \pm 0.159$ & $0.724 \pm 0.054$ \\
\hline
\end{tabular}

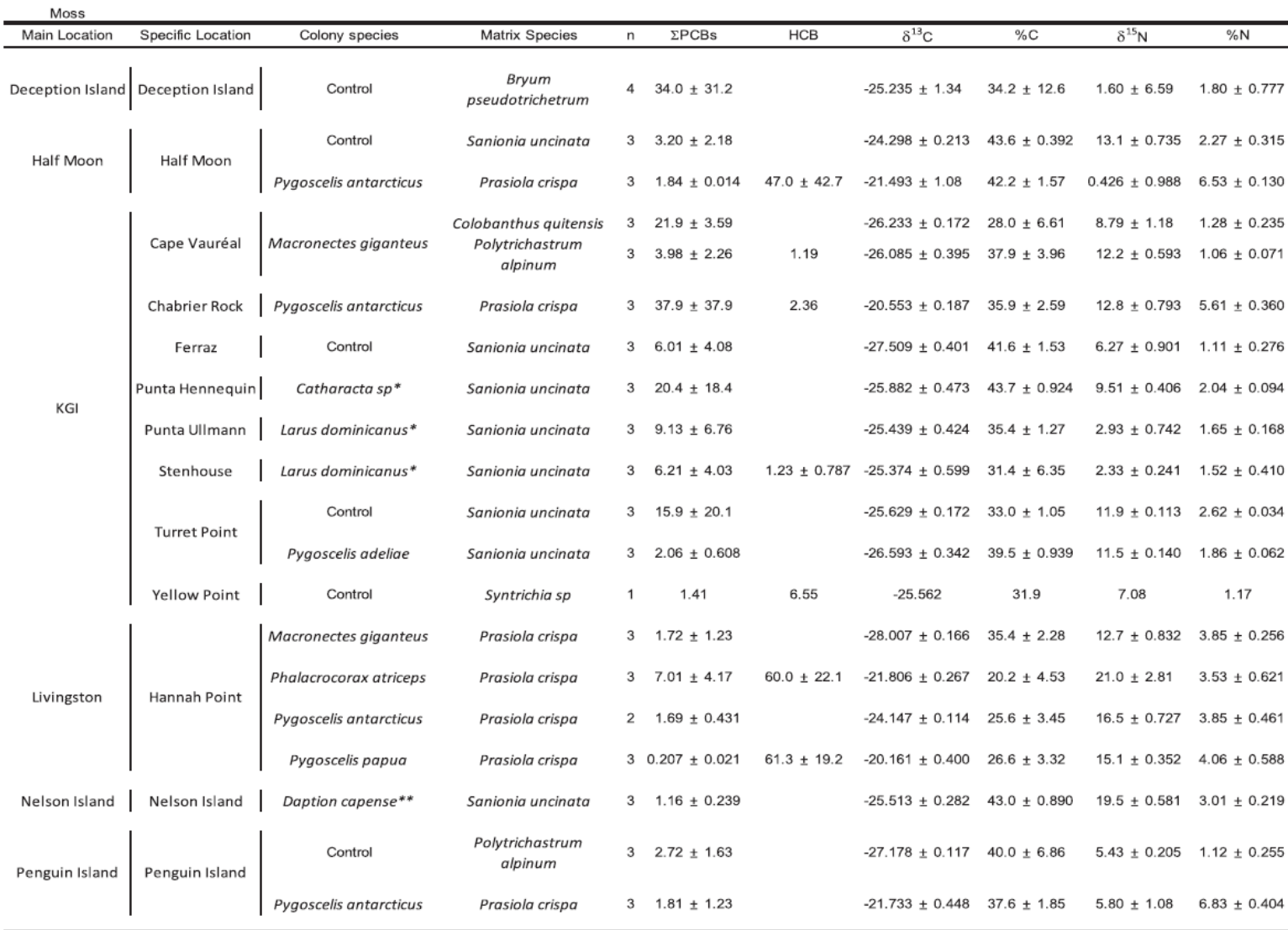




\begin{tabular}{|c|c|c|c|c|c|c|c|c|c|c|}
\hline Main Location & Specific Location & Colony species & Matrix Species & $n$ & $\Sigma \mathrm{PCBs}$ & $\mathrm{HCB}$ & $\delta^{13} \mathrm{C}$ & $\% \mathrm{C}$ & $\delta^{15} \mathrm{~N}$ & $\% \mathrm{~N}$ \\
\hline Deception Island | & Deception Island & Control & & 3 & $0.763 \pm 0.640$ & $0.956 \pm 0.440$ & $-25.752 \pm 0.234$ & $0.095 \pm 0.046$ & $29.6 \pm 3.12$ & $0.053 \pm 0.008$ \\
\hline Half Moon & Half Moon & | Pygoscelis antarcticus & & 3 & 0.420 & $404 \pm 470$ & $-28.470 \pm 0.529$ & $17.2 \pm 2.12$ & $20.1 \pm 0.942$ & $4.42 \pm 0.262$ \\
\hline \multirow{6}{*}{ KGI } & Chabrier Rock & | Pygoscelis antarcticus & & 3 & $2.14 \pm 1.46$ & $41.7 \pm 6.42$ & $-28.079 \pm 0.924$ & $21.6 \pm 1.98$ & $13.5 \pm 5.19$ & $9.58 \pm 4.48$ \\
\hline & Shag Island & | Phalacrocorax atriceps & & 3 & $1.96 \pm 0.693$ & & $-24.745 \pm 0.409$ & $9.87 \pm 1.40$ & $30.9 \pm 0.802$ & $2.76 \pm 0.408$ \\
\hline & & Control & & 3 & $3.62 \pm 2.97$ & 8.49 & $-23.414 \pm 0.294$ & $0.540 \pm 0.335$ & $13.0 \pm 7.42$ & $0.156 \pm 0.073$ \\
\hline & Turret Point & Phalacrocorax atriceps & & 3 & 0.380 & $578 \pm 655$ & $-24.508 \pm 0.401$ & $8.66 \pm 1.11$ & $30.7 \pm 0.718$ & $2.52 \pm 0.359$ \\
\hline & & Pygoscelis adeliae & & 3 & $5.88 \pm 9.53$ & $4.26 \pm 0.047$ & $-26.813 \pm 0.267$ & $9.65 \pm 2.24$ & $16.8 \pm 0.746$ & $2.03 \pm 0.458$ \\
\hline & Yellow Point & Control & & 1 & 0.960 & & -22.081 & 0.814 & 9.12 & 0.097 \\
\hline \multirow{3}{*}{ Livingston } & \multirow{3}{*}{ Hannah Point } & Phalacrocorax atriceps & & 3 & $1.92 \pm 1.70$ & & $-24.423 \pm 0.330$ & $7.54 \pm 1.42$ & $25.7 \pm 2.06$ & $1.94 \pm 0.626$ \\
\hline & & Pygoscelis antarcticus & & 3 & 1.87 & $18.8 \pm 4.80$ & $-28.139 \pm 0.317$ & $8.84 \pm 0.938$ & $18.8 \pm 0.137$ & $1.95 \pm 0.186$ \\
\hline & & Pygoscelis papua & & 3 & $2.23 \pm 2.64$ & $16.5 \pm 6.07$ & $-27.402 \pm 0.560$ & $1.55 \pm 0.127$ & $22.4 \pm 1.78$ & $0.523 \pm 0.051$ \\
\hline \multirow{2}{*}{ Penguin Island } & \multirow{2}{*}{ Penguin Island } & Control & & 3 & $1.04 \pm 0.332$ & 0.394 & $-22.317 \pm 0.232$ & $1.23 \pm 0.392$ & $18.8 \pm 0.441$ & $0.228 \pm 0.076$ \\
\hline & & Pygoscelis adeliae & & 3 & $12.5 \pm 16.5$ & & $-28.461 \pm 0.462$ & $24.6 \pm 2.22$ & $17.4 \pm 1.53$ & $5.72 \pm 0.637$ \\
\hline
\end{tabular}


Table 2. Significant Spearman correlations among the studied variables.

\begin{tabular}{|c|c|c|c|}
\hline & & Control sites & Colony sites \\
\hline \multirow[t]{5}{*}{ Lichen } & $\delta^{13} \mathrm{C}$ & & \\
\hline & $\% \mathrm{C}$ & $-\mathrm{HCB}$ & $+\mathrm{\Sigma PCBs},+\mathrm{HCB}$ \\
\hline & $\% \mathrm{~N}$ & + SPCBs & $+\delta^{15} \mathrm{~N},-\mathrm{HCB}$ \\
\hline & $\Sigma \mathrm{PCBS}$ & $+\% \mathrm{~N}$ & $+\% \mathrm{C},-\delta^{15} \mathrm{~N}$ \\
\hline & НСB & $-\% \mathrm{C}$ & $+\% \mathrm{C},-\delta^{-15} \mathrm{~N},-\% \mathrm{~N}$ \\
\hline \multirow[t]{4}{*}{ Moss } & $\delta^{13} \mathrm{C}$ & $+\% \mathrm{~N}$ & $+8 \mathrm{~N},+\mathrm{HCB}$ \\
\hline & $\begin{array}{l}\% \mathrm{C} \\
\delta^{15} \mathrm{~N}\end{array}$ & & \\
\hline & $\% \mathrm{~N}$ & $+\delta^{13} \mathrm{C}$ & $+\delta^{13} \mathrm{C},-\Sigma \mathrm{PCBs}$ \\
\hline & $\begin{array}{l}\text { ₹PCBS } \\
\text { HCB }\end{array}$ & & $\begin{array}{l}-8 \mathrm{~N} \\
+\delta^{13} \mathrm{C}\end{array}$ \\
\hline \multirow[t]{5}{*}{ Soil } & $\delta^{13} \mathrm{C}$ & $+\% \mathrm{C},-\delta^{15} \mathrm{~N},+\% \mathrm{~N}$ & $-\%,+\delta^{15} \mathrm{~N}$ \\
\hline & $\% \mathrm{C}$ & $+\delta^{13} \mathrm{C},-\delta^{15} \mathrm{~N},+\% \mathrm{~N}$ & $-\delta^{-13} \mathrm{C},-\delta^{-15} \mathrm{~N},+8 \mathrm{~N}$ \\
\hline & $\frac{9 N}{n}$ & $\begin{array}{l}-01,-6 \mathrm{C} \\
+\delta^{13} \mathrm{C},+\% \mathrm{C}\end{array}$ & $\begin{array}{l}+0.0,-\infty c \\
+\% C\end{array}$ \\
\hline & $\Sigma$ PCBS & & \\
\hline & НСB & & \\
\hline
\end{tabular}




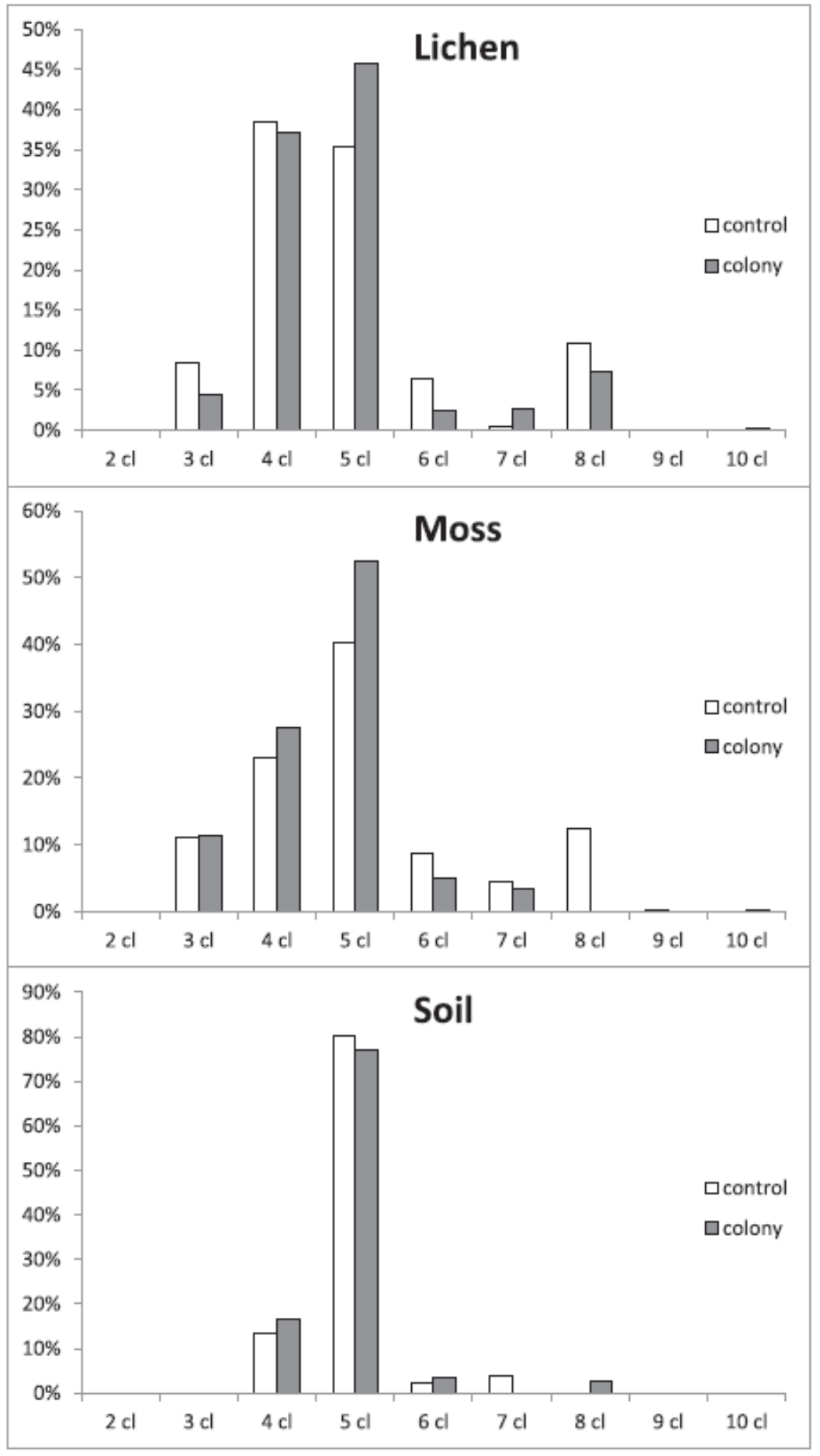

Figure 1. Relative average PCBs chlorination number in the sampled matrixes. 
Table 3

Parameters composition and relative weights (wi) for the most accurate model for each of the subsets according to AICc.

\begin{tabular}{|c|c|c|c|c|c|}
\hline & & \multicolumn{2}{|c|}{ PCBs } & \multicolumn{2}{|c|}{$\mathrm{HCB}$} \\
\hline & & parameters & $w_{i}$ & parameters & $w_{i}$ \\
\hline \multirow[t]{2}{*}{ Lichen } & control & Specific Location & 0.24 & - & - \\
\hline & colony & $\delta^{13} \mathrm{C}+\% \mathrm{C}$ & 0.74 & $\% C+$ Matrix Species & 0.44 \\
\hline \multirow[t]{2}{*}{ Moss } & control & $\% \mathrm{C}$ & 0.52 & - & - \\
\hline & colony & $\delta^{15} \mathrm{~N}$ & 0.41 & - & - \\
\hline \multirow[t]{2}{*}{ Soil } & control & Specific Location & 0.44 & - & - \\
\hline & colony & - & - & - & - \\
\hline
\end{tabular}


Table 4. Results for the t-tests of colony sites compared to the closest control site, by matrix. *, ** and $* * *$ stand for $\mathrm{p}=0.05,0.01$ and 0.001 respectively. Underline indicates control values higher than colony ones. Colony species marked with an * indicate very sparse colonies.

\begin{tabular}{|c|c|c|c|c|c|c|c|c|c|c|}
\hline Main Location & Specific Location & Colony species & Matrix Species & $n$ & $\Sigma \mathrm{PCBs}$ & $\mathrm{HCB}$ & $\delta^{13} \mathrm{C}(\%)$ & $\% \mathrm{C}$ & $\delta^{15} \mathrm{~N}(\%)$ & $\% \mathrm{~N}$ \\
\hline Half Moon & Half Moon & Pygoscelis antarcticus & Ramalina terebrata & 3 & $* *$ & & 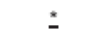 & & ** & * \\
\hline \multirow{5}{*}{ KGI } & Cape Vauréal & Macronectes giganteus | & Usnea antarctica & 3 & & & $\check{-}$ & & & $\star \star * \star$ \\
\hline & Punta Hennequin & Catharacta $s p^{*}$ & Usnea antarctica & 3 & & & $\approx *$ & & & $\star \star$ \\
\hline & Stenhouse & Larus dominicanus* & Usnea antarctica & 3 & & & $\varepsilon$ & & & $\star$ \\
\hline & Turret Point & Phalacrocorax atriceps & Ramalina terebrata & 3 & & & $\cdots$ & $\therefore$ & & \\
\hline & & Pygoscelis adeliae & Usnea antarctica & 3 & & & 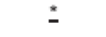 & & & \\
\hline \multirow{3}{*}{ Livingston } & \multirow{3}{*}{ Hannah Point } & \multirow{2}{*}{ Macronectes giganteus } & Ramalina terebrata & 2 & & & $* *$ & & & \\
\hline & & & Turgidiusculum complicatulum & 1 & & & $\cdots$ & $\ddot{-}$ & ** & ${ }^{\star \star * *}$ \\
\hline & & Pygoscelis papua & Ramalina terebrata & 3 & & & & & 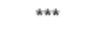 & $\star \star \star \star * A$ \\
\hline Nelson Island & Nelson Island & Daption capense ${ }^{* *}$ & Usnea aurantiaco-ater & 3 & & & $\underline{-}$ & & & ** \\
\hline Penguin Island & Penguin Island & Sterna vittata & Usnea aurantiaco-ater & 3 & & * & & $\stackrel{* *}{-}$ & $\stackrel{*}{-}$ & \\
\hline
\end{tabular}

\begin{tabular}{|c|c|c|c|c|c|c|c|c|c|}
\hline Main Location & Specific Location & Colony species & Matrix Species & $\mathrm{n}$ & $\Sigma \mathrm{PCBs} \mathrm{HCB}$ & $\delta^{13} \mathrm{C}(\%)$ & $\% \mathrm{C}$ & $\delta^{15} \mathrm{~N}(\%)$ & $\% \mathrm{~N}$ \\
\hline \multirow[t]{8}{*}{ Half Moon } & Half Moon & Pygoscelis antarcticus & Prasiola crispa & 3 & & $*$ & & $\star \star \star *$ & $\star \star \star$ \\
\hline & \multirow{2}{*}{ Cape Vauréal } & \multirow{2}{*}{ Macronectes giganteus } & Colobanthus quitensis & 3 & & $*$ & 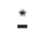 & * & \\
\hline & & & Polytrichastrum alpinum & 3 & & * & & 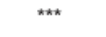 & \\
\hline & Chabrier Rock & Pygoscelis antarcticus & Prasiola crispa & 3 & & $* * *$ & $\stackrel{-}{-}$ & $\star \star \star \star$ & $\star \star \star$ \\
\hline & Punta Hennequin & Catharacta $s p^{*}$ & Sanionia uncinata & 3 & & $*$ & & $\star \star$ & $\star \star$ \\
\hline & Punta Ullmann & Larus dominicanus* & Sanionia uncinata & 3 & & $*$ & $\ddot{-}$ & $\star \star$ & $\star$ \\
\hline & Stenhouse & Larus dominicanus* & Sanionia uncinata & 3 & & $*$ & & \pm & \\
\hline & Turret Point & Pygoscelis adeliae & Sanionia uncinata & 3 & & - & $*$ & 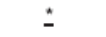 & $\stackrel{*+*}{ }$ \\
\hline \multirow{4}{*}{ Livingston } & \multirow{4}{*}{ Hannah Point } & Macronectes giganteus & Prasiola crispa & 3 & & $* *$ & $\ddot{-}$ & & $\star \star$ \\
\hline & & Phalacrocorax atriceps & Prasiola crispa & 3 & & $\cdots$ & 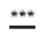 & $* *$ & * \\
\hline & & Pygoscelis antarcticus & Prasiola crispa & 2 & & & $\ddot{-}$ & * & * \\
\hline & & Pygoscelis papua & Prasiola crispa & 3 & & $\cdots$ & $\ddot{\cdots}$ & * & $\star *$ \\
\hline Nelson Island & Nelson Island & Daption capense ${ }^{* *}$ & Sanionia uncinata & 3 & & $*$ & & 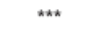 & $* \star * *$ \\
\hline Penguin Island & Penguin Island & Pygoscelis antarcticus & Prasiola crispa & 3 & & $* * *$ & & & 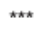 \\
\hline
\end{tabular}




\begin{tabular}{|c|c|c|c|c|c|c|c|c|}
\hline Main Location & Specific Location & Colony species & $n$ & EPCBS HCB & $\delta^{13} \mathrm{C}(\%)$ & $\% \mathrm{C}$ & $\delta^{15} \mathrm{~N}(\%)$ & $\% \mathrm{~N}$ \\
\hline Half Moon & Half Moon & | Pygoscelis antarcticus & 3 & & 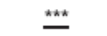 & $* * *$ & & $\cdots$ \\
\hline \multirow{4}{*}{ KGI } & Chabrier Rock & Pygoscelis antarcticus & 3 & & 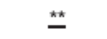 & $* * *$ & & * \\
\hline & Shag Island & | Phalacrocorax atriceps & 3 & & \pm & *** & * & $\cdots$ \\
\hline & \multirow{2}{*}{ Turret Point } & Phalacrocorax atriceps & 3 & & 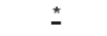 & *** & * & $\cdots$ \\
\hline & & Pygoscelis adeliae & 3 & $\ddot{-}$ & $\pm *$ & ** & & ** \\
\hline \multirow{3}{*}{ Livingston } & \multirow{3}{*}{ Hannah Point } & Phalacrocorax atriceps & 3 & & 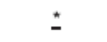 & $*$ & $*$ & $*$ \\
\hline & & Pygoscelis antarcticus & 3 & & 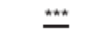 & $* *$ & & $\cdots$ \\
\hline & & Pygoscelis papua & 3 & & 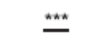 & $* *$ & & $*$ \\
\hline Penguin Island | & Penguin Island & Pygoscelis adeliae & 3 & & 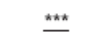 & $* * *$ & & $\cdots$ \\
\hline
\end{tabular}

